\title{
EXPERIMENTAÇÃO, CIÊNCIA E ENSINO: CONCEPÇÕES E RELAÇÕES NA FORMAÇÃO INICIAL DE PROFESSORES DO PETCIÊNCIAS
}

\author{
EXPERIMENTATION, SCIENCE AND EDUCATION: CONCEPTION AND \\ RELATIONS IN INITIAL TEACHING FORMATION OF PETCIÊNCIAS
}

\author{
Daniele Bremm ${ }^{1}$ \\ Lenice Heloísa de Arruda Silva ${ }^{2}$ \\ Roque Ismael da Costa Güllich ${ }^{3}$
}

\begin{abstract}
Resumo: Este artigo apresenta e analisa as concepções e relações de experimentação, Ciência e ensino pertencentes a professores de Ciências em formação inicial, participantes do Programa de Educação Tutorial (PETCiências). Foi possível verificar que os licenciandos compreendem a importância das atividades experimentais para a aprendizagem, sendo mais frequente a concepção de experimentação contextual-investigativa; já as concepções de Ciência e de ensino ainda estão em nível tradicional, mas apresentam certa tendência à evolução para perspectivas mais transformadoras e contextuais. Percebemos a importância da reflexão sobre a própria prática, por meio da escrita narrativa e apostamos no potencial do PETCiências como coletivo importante no processo de formação inicial, permitindo o diálogo intermitente entre prática e a teoria.
\end{abstract}

Palavras-chaves: Investigação-formação-ação; Escrita reflexiva; Ensino de Ciências.

Abstract: This article presents and analyzes experimentation conceptions and interrelationships, Science and education that belongs to Science teachers in initial formation, who are part of the Tutorial Education Program (PETCiências). It was possible to verify that teachers in formation understand the importance of experimental activities to improve learning, being more frequent the investigative-contextual conception of experimentation, conceptions of science and teaching are still at the traditional level, but they tend to evolve towards more transformative and contextual perspectives. Science and teaching conception are still at the traditional level, but they already present a certain bias to evolution to a more transforming and contextual perspective. We notice the importance of thinking about your own practice, through narrative writing and we bet in PETCiências' potential as an important collective in the initial formation process, allowing intermittent dialogue between practice and theory.

Keywords: Investigation-Formation-Action; Reflective writing; Science Teaching.

\footnotetext{
${ }^{1}$ Mestranda em Ensino de Ciências pela Universidade Federal da Fronteira Sul (UFFS), Cerro Largo, Rio Grande do Sul, Brasil. E-mail: bremmdaniele@gmail.com

${ }^{2}$ Doutora em Educação pela Universidade Metodista de Piracicaba (UNIMEP). Professora da Universidade Federal da Grande Dourados (UFGD), Dourados, Mato Grosso do Sul, Brasil. E-mail: leniceheloisa@gmail.com

${ }^{3}$ Doutor em Educação nas Ciências, Universidade Regional do Noroeste do Estado do Rio Grande do Sul (UNIJUÍ). Professor da Universidade Federal da Fronteira Sul (UFFS), Cerro Largo, Rio Grande do Sul, Brasil. E-mail: bioroque.girua@gmail.com
} 


\section{Introdução}

Há certo consenso de que nas aulas de Ciências as atividades de experimentação são indispensáveis, pois experimentar permite a interação do aluno com o objeto de estudo e com os demais sujeitos (professor e colegas) presentes nesse contexto, bem como ajuda na elaboração de conhecimentos (CARVALHO et al., 2007). Nesse sentido, a maneira como os professores desenvolvem tais atividades será um diferencial, que poderá vir ou não a favorecer esse processo. Nessa perspectiva, a postura que precisa ser tomada pelo professor é a de auxiliar os alunos na exploração dos processos envolvidos no transcurso das atividades experimentais, no desenvolvimento de suas concepções e no estudo dos fenômenos e conceitos científicos (HODSON, 1994).

Entretanto, muitas pesquisas têm demostrado que as atividades experimentais não estão sendo realizadas de maneira satisfatória, no sentido de contribuir efetivamente para o processo de ensino-aprendizagem de Ciências. Segundo Silva e Zanon (2000), isso se deve à formação inicial restrita que os professores de Ciências tiveram sobre o assunto, acarretando concepções equivocadas e simplistas sobre a experimentação (FAGUNDES, 2007). Nesses termos, tratando-se de experimentação, sempre estaremos nos remetendo às concepções dos professores acerca do que ensinam e do que é Ciência para eles. Por isso, estudos sobre a experimentação tendem a contribuir para o desenvolvimento de novos significados de seu papel no ensino de ciências (ROSITO, 2008).

Trabalhar com experimentação agrega qualidade à prática docente em Ciências, pois uma boa pergunta mediada pelo professor ajuda o aluno a formular hipóteses e responder os questionamentos abordados durante o processo experimental (RIBAS; UHMANN, 2013). A mediação em um processo de experimentação proposta como investigativa é necessária e desafiadora, uma vez que ainda estamos em uma cultura acadêmica que não leva em conta importantes discussões conceituais sobre o que é Ciência (MOTTA et al., 2013). Os questionamentos abordados durante o processo experimental são indispensáveis para gerar o diálogo formativo (RIBAS; UHMANN, 2013; GÜLLICH, 2013).

Segundo Rosito (2008), a experimentação é importante no ensino de Ciências, pois permite a interação entre professor e aluno durante as aulas práticas, proporcionando um planejamento conjunto e o uso de técnicas de ensino que levam a uma melhor compreensão da Ciência. "Contudo, mesmo sendo consideradas essenciais ao ensino de 


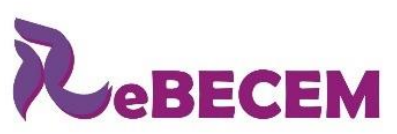

Revista Brasileira de Educação em

Ciências e Educação Matemática

DOI: http://dx.doi.org/10.33238/ReBECEM.2020.v.4.n.1.24227

Ciências, as práticas experimentais nem sempre têm lugar reconhecido no currículo" (WYZYKOWSKI; GÜLLICH; ARAÚJO, 2016, p.38).

Os professores de Ciências têm consciência da importância da experimentação para a aprendizagem, mas não possuem clareza e consenso sobre os objetivos da experimentação (SILVA; ZANON, 2000; ROSITO, 2008). Nesse sentido, julgamos importante que na formação inicial sejam criados espaços para que os futuros professores possam dialogar sobre concepções de Ciência e de experimentação no ensino de Ciências. Em função disso, decidimos investigar e analisar o transcurso das ressignificações de concepções de experimentação, Ciência e ensino na formação inicial de professores de Ciências que participam de um coletivo de formação, a saber: Programa de Educação Tutorial - PETCiências ${ }^{4}$.

\section{Procedimentos metodológicos da investigação}

O presente trabalho se insere na área de Educação nas Ciências, pautando-se em uma abordagem qualitativa, cujos resultados advêm da análise de escritas produzidas por professores em formação inicial, com base na seguinte pergunta: Qual o papel da experimentação no ensino de Ciências? Estas escritas foram produzidas por 16 licenciandos ao longo do segundo semestre letivo de 2017 no Facebook ${ }^{5}$, do PETCiências, ao passo em que participavam de encontros semanais, no Laboratório de Ensino e Aprendizagem I, da Universidade Federal da Fronteira Sul- UFFS, local onde o grupo possui sala própria. Em tais encontros foram discutidos vários artigos com o tema experimentação, no intuito de levantar quais eram as concepções de experimentação apresentadas pelos autores, assim como realizar debates e socializações de ideias, buscando, no diálogo formativo e por meio de escritas reflexivas, aprimorar suas concepções sobre experimentação.

Segundo Alarcão (2010), é a escrita que desencadeia o hábito reflexivo e, portanto, esta deve ser denominada de escrita reflexiva. A escrita reflexiva é uma ferramenta que na formação de professores permite a investigação acerca da própria

\footnotetext{
${ }^{4}$ Programa de Educação Tutorial, desenvolvido na Universidade Federal da Fronteira Sul (UFFS), Campus de Cerro Largo, RS, BR, que atua dentro de três eixos de formação: ensino, pesquisa e extensão. Financiado por: MEC- SESu - FNDE.

${ }^{5}$ Rede social, organizada na web, que possibilita a criação de grupos fechados para a discussão de temas de formação, adaptado a realidade do PETCiências, no qual é utilizado como ferramenta de formação, neste caso para produção de escritas reflexivas.
} 
DOI: http://dx.doi.org/10.33238/ReBECEM.2020.v.4.n.1.24227

prática (GÜLLICH, 2013). Por meio da escrita, o professor reflete e se desenvolve, resgatando conceitos e perspectivas já sabidas, pois a escrita reflexiva, que pode ser realizada tanto nos diários de formação quanto em outros espaços/instrumentos formativos, permite o distanciamento da ação em si, para analisar os fatos e reconstruílos retrospectiva e prospectivamente (ALARCÃO, 2010), assim se constitui em um elemento pelo qual o professor consegue articular melhor a sua reflexão (GÜLLICH, 2013; PORLÁN; MARTÍN, 2001).

A metodologia de análise empregada tem abordagem qualitativa, é do tipo documental e segue análise temática de conteúdos. São considerados documentos quaisquer materiais escritos que possam ser usados como fonte de informação sobre o comportamento humano (PHILLIPS, 1974, p. 187). Este tipo de análise busca identificar informações factuais nos documentos a partir de questões ou hipóteses de interesse (LÜDKE; ANDRÉ 2001). A análise de conteúdo é definida por Krippendorff (1980, p. 21, apud LÜDKE; ANDRÉ 2001, p. 41) como "uma técnica de pesquisa para fazer inferências válidas e replicáveis dos dados para o seu contexto". Assim, são selecionados elementos específicos do conteúdo para a realização da análise, explorando o contexto em que uma determinada unidade ocorre. Depois de organizar os dados, o pesquisador pode voltar a examiná-los para tentar detectar temáticas mais frequentes. Esse procedimento vai culminar na construção de categorias.

Para a análise das narrativas em contexto, procedemos com leituras preliminares sobre o assunto e posteriormente ocorreu o estabelecimento de categorização temática de conteúdo através de três estapas: pré-análise, exploração do material e o tratamento dos resultados e interpretação (LÜDKE; ANDRÉ 2001). Para tal, realizamos inicialmente a coleta de excertos, digitação e marcação de trechos para verificar as concepções, que foram posteriormente categorizadas dando possibilidades de interpretação e produção dos resultados. Seguimos principalmente os referenciais de Silva e Zanon (2000), Motta et al. (2013), Ramos; Antunes e Silva (2010), Wyzykowski e Güllich (2012), Habermas (2006) e Rosa e Schnetzler (2003) sobre a concepções de: Experimentação, Ciência e Ensino.

Os sujeitos da investigação são participantes do PETCiências, que abrange licenciandos de três cursos de Licenciatura: Ciências Biológicas, Física e Química. Dentro deste programa, os petianos participam de diversas atividades para qualificar sua formação, entre elas podemos citar algumas bem importantes: i) atividades de leitura, diálogo e escrita de referências teóricas sobre Ciências, Pesquisa e Experimentação; ii) a participação no projeto de Extensão - Ciclos formativos no Ensino de Ciências do Grupo 
DOI: http://dx.doi.org/10.33238/ReBECEM.2020.v.4.n.1.24227

de Estudos e Pesquisa em Ensino de Ciências e Matemática (GEPECIEM) e, iii) a iniciação à docência por meio do acompanhamento e auxílio a professores de Ciências das escolas de educação básica, momento em que têm a oportunidade de desenvolverem atividades experimentais com os alunos.

Os participantes do programa aceitaram livremente participar da pesquisa como sujeitos da investigação, autorizando a coleta de informações sobre suas concepções, sendo seus nomes trocados pela expressão "L" (Licenciando), seguido de um número de identificação, preservando as suas identidades.

\section{Resultados e discussão}

A produção e análise dos resultados desta investigação demonstrou a necessidade de explicitarmos o perfil dos sujeitos investigados e que participaram do mesmo coletivo de formação já mencionado: o PETCiências. Tais dados estão disponíveis na Tabela 1. De modo geral, foram analisadas concepções de 16 professores em formação inicial. Destes, nove eram do curso de Ciências Biológicas, quatro do curso de Química e três do curso de Física, todos de licenciatura.

Tabela 1: Informações sobre os sujeitos investigados

\begin{tabular}{|c|c|c|c|}
\hline Licenciando & Curso & Fase & $\begin{array}{l}\text { Tempo no } \\
\text { PETCiências }\end{array}$ \\
\hline L1 & Química & $2^{a}$ fase & meio ano \\
\hline $\mathbf{L} 2$ & C. Biológicas & $6^{\mathrm{a}}$ fase & 2 anos \\
\hline L3 & C. Biológicas & $6^{\mathrm{a}}$ fase & 2 anos e meio \\
\hline L4 & C. Biológicas & Indefinida & 2 anos e meio \\
\hline L5 & Física & $6^{\mathrm{a}}$ fase & 1 ano e meio \\
\hline L6 & C. Biológicas & $4^{\mathrm{a}}$ fase & 1 ano \\
\hline L7 & C. Biológicas & $6^{\mathrm{a}}$ fase & 2 anos \\
\hline L8 & C. Biológicas & Indefinida & 3 anos \\
\hline L9 & Química & $8^{a}$ fase & 2 anos e meio \\
\hline L10 & C. Biológicas & $2^{a}$ fase & meio ano \\
\hline L11 & Química & $4^{\mathrm{a}}$ fase & 1 ano \\
\hline L12 & Física & $8^{a}$ fase & 3 anos \\
\hline L13 & C. Biológicas & $6^{\mathrm{a}}$ fase & meio ano \\
\hline L14 & C. Biológicas & $2^{a}$ fase & meio ano \\
\hline L15 & Química & $8^{\mathrm{a}}$ fase & 4 anos \\
\hline L16 & Física & $8^{\mathrm{a}}$ Fase & 1 ano \\
\hline
\end{tabular}

Fonte: Elaborado pelos autores

Segundo estudos e pesquisas na área do ensino de ciências, as concepções de experimentação geralmente se pautam nas seguintes categorias: Comprovação da teoria, Demonstração da teoria, Complementação da teoria, Sinônimo de motivação e Contextual-investigativa (SILVA; ZANON, 2000; WYZYKOWSKI; GÜLLICH, 2012). 


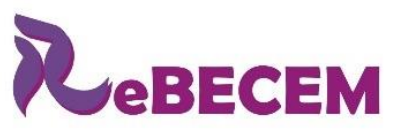

Revista Brasileira de Educação em

Ciências e Educação Matemática

DOI: http://dx.doi.org/10.33238/ReBECEM.2020.v.4.n.1.24227

A concepção de experimentação como Comprovação da teoria está voltada àquelas atividades em que a experimentação é utilizada após a ministração de conteúdos teóricos, apenas como forma de comprovar a teoria que foi explanada anteriormente em sala de aula, ocorrendo de forma irreflexiva, baseada em verdades já estabelecidas, sem levar em conta a construção de conhecimentos conceituais (SILVA; ZANON, 2000). A concepção de experimentação como uma forma de Demonstração da teoria está ligada a atividades que buscam demonstrar aspectos do conteúdo estudado, podendo ocorrer antes da teoria ser ministrada, como forma de introduzir o conteúdo, ou, depois da teoria, como forma de relembrar os conteúdos abordados (WYZYKOWSKI; GÜLLICH, 2012).

A Complementação da teoria está voltada a atividades em que a experimentação é utilizada como forma de clarear aquilo que está sendo trabalhando na teoria. Assim sendo o experimento é utilizado durante a aula apenas de forma a complementar o que já foi explicado (WYZYKOWSKI; GÜLLICH, 2012). Compreendemos que a atividade experimental está sendo realizada como Sinônimo de motivação quando esta é utilizada apenas com o princípio de despertar o interesse dos alunos, preterindo a importância da compreensão dos fenômenos que envolvem a atividade e, portanto, a aprendizagem dos alunos (SILVA; ZANON, 2000).

A concepção de experimentação Contextual-Investigativa está voltada às atividades em que importam os conhecimentos dos alunos e o contexto social dos mesmos. Estas atividades fazem uso do experimento como forma de diálogo entre a teoria e a prática, exigindo que ocorra reflexão por parte dos alunos. Neste tipo de atividade, os alunos atuam buscando encontrar respostas, por meio do desenvolvimento do experimento, para as perguntas que o professor lança durante a aula, ao longo desse processo os conceitos que envolvem o experimento são comprrendidos (Wyzykowski; Güllich, 2012; MOTTA et al., 2013; GÜLLICH; WALCZAK; MATTOS, 2019).

Analisando as escritas reflexivas dos licenciandos, nas quais eles responderam à pergunta: “Qual o papel da experimentação no ensino de Ciências?”, podemos constatar que os mesmos apresentam, no mínimo, cinco concepções distintas a respeito do tema experimentação no ensino de Ciências, sendo estas: concepção contextual- investigativa, sinônimo de motivação, comprovação da teoria, complementação da teoria e demonstração da teoria. Isso pode ser verificado na Figura 1. 


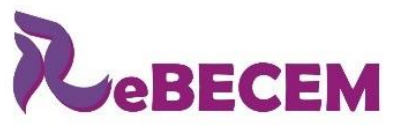

Revista Brasileira de Educação em

Ciências e Educação Matemática

ISSN 2594-9179

DOI: http://dx.doi.org/10.33238/ReBECEM.2020.v.4.n.1.24227

Figura 1: Gráfico de categorização das concepções de experimentação

\title{
Concepções de experimentação
}

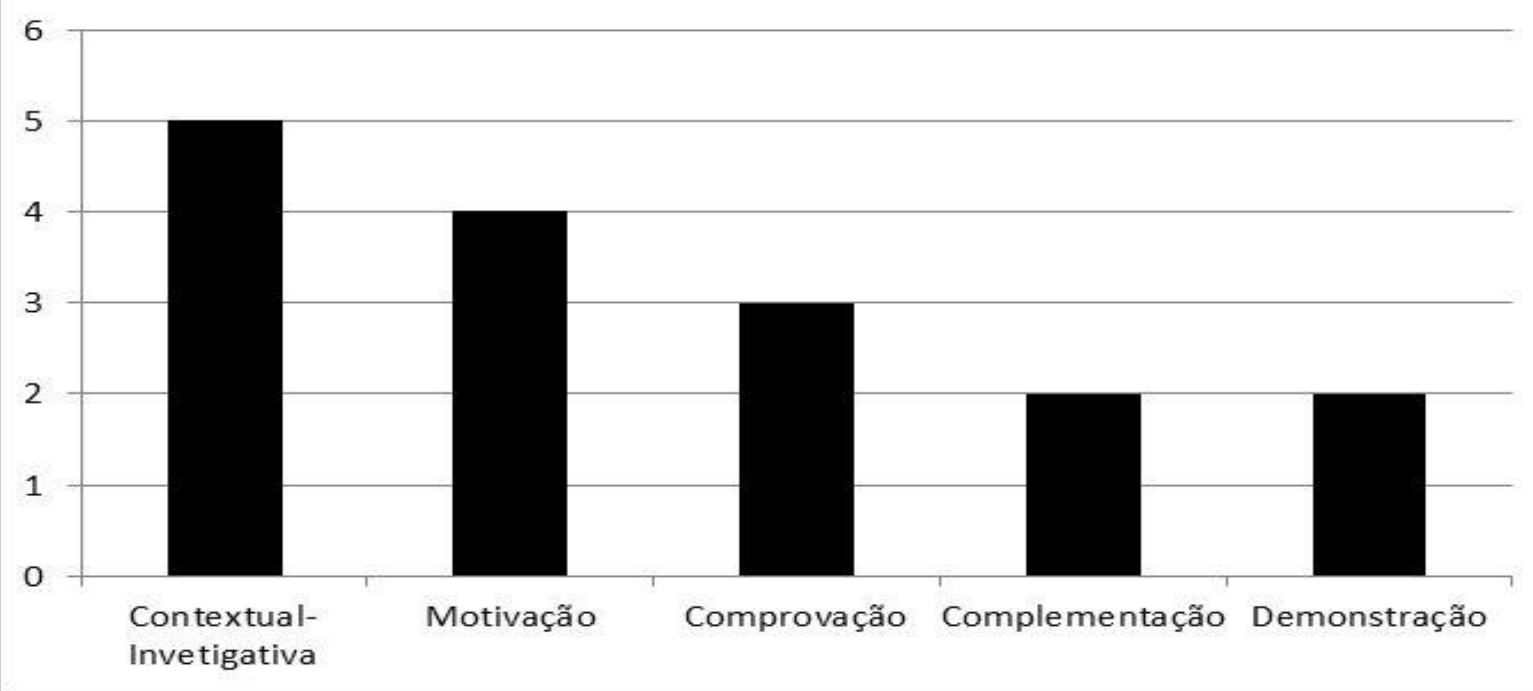

Fonte: Elaborado pelos autores

Alguns dos sujeitos da investigação apresentavam mais de uma concepção em seus excertos, no entanto ficou evidenciado que uma delas se sobressaía. Nesse sentido, dos dezesseis petianos que tiveram seus excertos narrativos analisados, cinco concebiam a experimentação como Contextual - Investigativa.

Esses petianos evidenciaram apresentar ideias mais críticas sobre a experimentação, demonstrando que refletiram muito sobre esse tema. Como podemos observar na escrita do Licenciando 9:

\begin{abstract}
A experimentação no ensino de Ciências, em todas as subáreas que integram a área de CNT ${ }^{6}$, auxilia na problematização dos conceitos/conteúdos trabalhados no estudo de determinada temática. Possibilita uma maior interação entre sujeitos na produção de conhecimentos e desse modo pela mediação qualificada do professor conhecimentos significativos e que de fato façam sentido para os alunos ${ }^{7}$ (L9).
\end{abstract}

A escrita que o Licenciando 9 faz sobre a experimentação denota a importância do processo de reflexão proporcionado pelo espaço de interação, leituras e reflexão do PETCiências, culminando em um pensamento mais elaborado sobre o tema. Percebemos, assim, que a vivência de L9 (dois anos e meio) nesse contexto é formativa e constitutiva do sujeito professor. Isso se torna importante principalmente na formação inicial, pois a partir do momento em que o aluno passa a refletir sobre as práticas experimentais, a tendência pode ser sempre melhorá-las num contexto de ensino, que se constitui, assim,

\footnotetext{
${ }^{6}$ Ciências da Natureza e suas Tecnologias.

${ }^{7}$ Neste texto, optamos por usar o destaque tipográfico itálico para todas as escritas reflexivas dos sujeitos investigados, valorizando as manifestações dos licenciandos e o material coletado na pesquisa.
} 
DOI: http://dx.doi.org/10.33238/ReBECEM.2020.v.4.n.1.24227

um processo de investigação-formação-ação (GÜLLICH, 2013), que permite ao aluno aperfeiçoar a sua concepção de experimentação. Tal perspectiva também pode ser observada por meio do excerto da escrita de L13, que tem meio ano de PETCiências:

Vejo a experimentação para o ensino de Ciências, como uma forma de facilitar a compreensão dos alunos, desmistificando muitas vezes a Ciência como algo concreto e absoluto, porém para isso o experimento deve ser planejado e bem elaborado, de modo que instigue os alunos a refletir, questionar, criticar, levantar hipóteses, refutá-las e investigar. A experimentação investigativa possibilita e facilita a construção de novos e significativos conhecimentos (L13).

Podemos perceber que os licenciandos que apresentam a concepção contextualinvestigativa parecem compreender que, para que as atividades de práticas experimentais cumprirem o seu papel de aprendizagem de conceitos, é preciso que o professor compreenda a importância de desenvolver essas aulas de forma que a teoria e a prática dialoguem. Além disso, é importante que: i) a aula seja muito bem planejada para que haja contextualização do tema; ii) questionamentos sejam realizados de forma a instigar o diálogo e a formação de hipóteses; iii) a produção de algum material referente à atividade; iv) haja tempo para a socialização dos argumentos formados pelos grupos e, por fim, v) haja reflexões sobre o desenvolvimento da prática (WYZYKOWSKI; GÜLLICH, 2012; MOTTA et al., 2013). É a partir dessa reflexão sobre a sua prática e sobre o processo de ensino, que as concepções dos licenciandos vão se desenvolvendo. Segundo Trivelato e Tonidandel (2015, p.106), “um estudante que saiba construir seus argumentos ao fazer afirmações ou declarações sobre fenômenos da natureza está aprendendo ciências".

As ideias acima apresentadas também ficam evidentes quando observamos que os petianos que apresentam a concepção contextual-investigativa sobre a experimentação, são os petianos que já estão há mais tempo participando do PETCiências, como é o caso de L9 (dois anos e meio) e L12 (três anos), ou são petianos que fazem/fizeram pesquisa sobre o tema durante sua participação no programa como L5 (um ano e meio), L13 (meio ano) e L16 (um ano), o que parece explicar o avanço destes últimos em menos tempo. Portanto, já tiveram contato com a literatura acerca da experimentação durante a sua participação por meio das leituras do próprio PETCiências e nos Ciclos Formativos do GEPECIEM. Assim, como estão há certo tempo escrevendo em seus diários de bordo, refletindo sobre as suas práticas e os eventos de formação, conseguiram, assim, avançar nas suas concepções a respeito do tema experimentação. Tal fato pode ser evidenciado no excerto de um licenciando que participa do PETCiências há três anos: 
DOI: http://dx.doi.org/10.33238/ReBECEM.2020.v.4.n.1.24227

A experimentação no ensino de ciências é uma metodologia de ensino muito utilizada, pois a partir da mesma é possivel visualizar fenômenos, construir conceitos e então facilitar a construção dos conhecimentos dos estudantes. No entanto, algo muito questionado na experimentação é a famosa receita de bolo, na qual se segue vários passos (sem refletir sobre os mesmos) para se chegar num resultado previsto pela teoria, ou seja, acaba ocorrendo uma preocupação maior em chegar ao chamado resultado correto, quando na verdade não existem resultados corretos. A experimentação no ensino de ciências deve ser um momento de reflexão, na qual não pode existir uma receita de bolo a serem seguidas, apenas algumas orientações para que os estudantes possam por si mesmo realizar o experimento e questionar seus resultados (L12).

Outros petianos, que também estão há bastante tempo no programa, apresentaram, no entanto, concepções mais simplistas a respeito do tema experimentação. Acreditamos que isto se deva ao fato de que, como afirma Tardif (2002, p. 260), uma boa parte do que os professores compreendem sobre o ensino e seu papel é proveniente de suas próprias histórias de vida e, principalmente, de suas histórias como alunos. O autor explica que, diferentemente de outros profissionais, o professor foi imerso em seu campo profissional antes mesmo de começar a trabalhar. Tal imersão se manifesta por meio de toda uma bagagem de conhecimentos anteriores, de crenças, de representações e de certezas sobre a prática pedagógica que permanecem fortes e estáveis ao longo do tempo. Assim, quando começam a trabalhar como professores, são principalmente essas crenças que eles reativam para solucionar seus problemas profissionais. A partir disso, consideramos que as concepções são passíveis de retrocessos, mas podem avançar com as reflexões feitas nos diários de bordo e do contato com a literatura da área. Portanto, se o licenciando não faz uso da reflexão, subsidiada teoricamente, suas concepções tenderão a se manter simplistas.

A concepção de experimentação como Sinônimo de Motivação foi a segunda que mais emergiu da análise dos excertos das escritas dos licenciandos. Dos dezesseis investigados, quatro apresentavam essa concepção:

A experimentação é uma das inúmeras ferramentas que se bem utilizada e planejada pelo professor, torna o processo de aprender muito mais interessante, motivador e significativo ao aluno [...], motivando-os com isso a querer aprender sempre mais e querer buscar esse aprendizado além dá sala de aula (L2).

$\mathrm{Na}$ literatura encontramos defesa do poder de motivação que o uso de atividades experimentais exerce sobre os alunos. Segundo Oliveira (2010, p. 141): “a motivação é, sem dúvida, uma contribuição importante, sobretudo na tentativa de despertar a atenção de alunos mais dispersos na aula, envolvendo-os com uma atividade que lhes estimulem a querer compreender os conteúdos da disciplina". No entanto, existem controvérsias, 


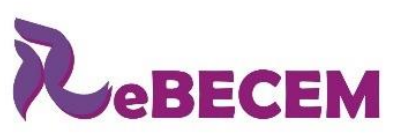

Revista Brasileira de Educação em

Ciências e Educação Matemática

DOI: http://dx.doi.org/10.33238/ReBECEM.2020.v.4.n.1.24227

pois a motivação dos alunos não deve ser o fator principal que leva um professor a elaborar um experimento, nem tampouco o seu papel principal. A aula experimental não pode ser vista como um mero show, este tipo de atividade só leva em conta a surpresa do experimento, não motiva o estudo dos fenômenos, o conhecimento que subjaz aos experimentos precisa ser problematizado (GONÇALVES; GALIAZZI, 2004).

Defendemos que o propósito das aulas experimentais não deve ser a motivação, ocasionada pelo entretenimento que proporciona, mas a produção de atividades de ensino que propiciem aprendizagem, interações, cooperação em atividades em grupos, entre outros objetivos. Porém, percebemos que as atividades experimentais são capazes de atrair o aluno para o que está acontecendo em sala de aula, de modo que ele esteja atento e se interesse, favorecendo a aprendizagem. Embora o foco principal das aulas experimentais não deva ser a motivação, o professor deve saber fazer uso deste artifício, para, assim, chegar ao real propósito desse tipo de aula: a aprendizagem/significação dos conceitos. Como vemos no excerto a seguir:

A experimentação nessas três áreas desperta o interesse dos alunos, assim como facilita a compreensão e entendimento de conceitos que muitas vezes são abstratos, ou fenômenos que ocorrem no seu dia a dia. A experimentação também permite mais interação entre professor e aluno, pois durante as observações surgem questionamentos (L7).

A terceira concepção a respeito da experimentação que verificamos nos excertos foi a experimentação como Comprovação da Teoria, que se sobressaiu nos excertos de três petianos. Como podemos evidenciar na escrita reflexiva do L1:

A experimentação no ensino de Ciências é despertar no aluno, em diferentes níveis de escolaridade, o interesse pelo conteúdo, após a aprendizagem da teoria. O que antes era apenas uma teoria torna-se concreto, mas também é um desafio, pois é preciso ter uma base teórica para se comprovar essas hipóteses posteriormente (L1).

Podemos verificar que fica clara a ideia do licenciando de que a experimentação vai comprovar a teoria. Porém, essa concepção de experimentação está, a nosso ver, equivocada, uma vez que na mesma o ato experimental é tratado como algo físico, ou seja, ocorre de maneira irreflexiva, apenas para comprovar verdades já estabelecidas, não ocorrendo a construção de conhecimentos conceituais (SILVA; ZANON, 2000).

A experimentação desenvolvida como método para comprovar a teoria "torna-se uma atividade sem cunho pedagógico investigativo na direção contrária do potencial objetivo da experimentação, seja ele: ensinar conceitos" (WYZYKOWSKI; GÜLLICH, 2012). Devemos levar em conta também que a Ciência não é definitiva: muitas vezes, ao se realizar um experimento, os resultados são diferentes do esperado. Portanto, a 
DOI: http://dx.doi.org/10.33238/ReBECEM.2020.v.4.n.1.24227

experimentação não pode ser vista apenas como uma forma de reprodução de uma teoria a ser comprovada. Abordando a questão da comprovação de teorias em atividades experimentais, Güllich e Silva destacam que:

É preciso que o professor de Ciências tenha entendimento de que as práticas pedagógicas de experimentação no ensino de Ciências necessitam ser conduzidas pelo diálogo, que o importante é o processo e não somente os produtos de uma prática, que a escrita e o questionamento são possibilidades de registro e exercício da crítica e, por fim, que reconheça o papel da experimentação contextualizada e não apenas como um momento de comprovação de teorias (GÜLLICH; SILVA, 2013, p.160).

As concepções que menos emergiram nos excertos dos licenciandos foram a concepção de experimentação como Complementação da Teoria e a experimentação como Demonstração da Teoria. Dos dezesseis licenciandos investigados, dois apresentavam a concepção de experimentação como Complementação da Teoria. Neste tipo de concepção, o licenciando apenas faz uso das aulas experimentais para complementar aquilo que já foi trabalhado de forma teórica, ou seja, complementar um conceito através da prática experimental, no intuito de deixar o mesmo mais claro, como fica evidente no excerto:

Tem importante papel em aliar o empírico e o teórico, visto que a elucidação pelos alunos é mais facilitada quando isto acontece. Preposições podem ser incorporadas, relacionando fenômenos, teorias e etc., fugindo de uma teoria metódica (apenas) que é desinteressante no processo ensino-aprendizagem (L14).

A ideia de Experimentação como Demonstração da Teoria foi notada em dois dos dezesseis licenciandos investigados. Essa concepção se caracteriza pelos experimentos em que o professor executa e os alunos apenas observam. É utilizada para demonstrar aspectos do conteúdo estudado, sendo que neste tipo de experimento a demonstração pode ocorrer tanto antes, despertando o interesse para o tema, quanto depois da teoria, como forma de relembrar os conteúdos abordados (ARAÚJO; ABIB, 2003).

Nessa concepção, o professor é o agente do processo, cabe a ele elaborar o experimento, juntar os materiais, aplicá-lo, destacar o que deve ser observado e fazer questões para os alunos (GASPAR; MONTEIRO, 2005), os quais são pouco instigados a pensar e discutir hipóteses. Tal ideia parece se aproximar do que é expresso no excerto a seguir:

Creio que a experimentação nessas três áreas cumpre o papel de demonstração do conteúdo de modo prático facilitando o conhecimento e fazendo com que haja uma maior interação entre aluno e professor, quando observamos algo, sentimos, cheiramos, tocamos, estamos "conhecendo" de modo mais abrangente o que antes só ouvíamos (L7). 
DOI: http://dx.doi.org/10.33238/ReBECEM.2020.v.4.n.1.24227

Destacamos que, mesmo a experimentação demonstrativa sendo muito fechada e voltada para a explanação de um conteúdo apenas, ela pode se tornar uma boa ferramenta de aprendizagem se mediada da forma correta, permitindo que os alunos formulem suas hipóteses e dialoguem sobre elas relacionando com os conteúdos científicos, refletindo sobre os fenômenos do experimento. Desta forma, o aluno começa a se tornar mais ativo na aula, a qual pode se assemelhar ao método investigativo de experimentação. Tudo depende da mediação do professor, até mesmo o modelo investigativo "pode ser planejado e implementado com diferentes níveis de abertura, o que atribui aos estudantes, maior ou menor autonomia para conduzir as etapas do processo investigativo e, consequentemente, pode influenciar sua capacidade de promover o aprendizado" (SILVA; GEROLIN; TRIVELATO, 2018, p. 307).

Partindo dessa linha de raciocínio, a concepção mais aceita para as aulas experimentais é a que se denomina experimentação Contextual ou investigativa, conforme já mencionado antes, caracterizada por não apresentar um roteiro a ser seguido pelos alunos, nem resultados específicos a se chegar, deixando o aluno desenvolver a sua autonomia e decidir como procederá com o experimento, interpretando os resultados aos quais chegou. "Estes experimentos priorizam a autonomia dos alunos, mediando o desenvolvimento de pesquisas, análises, reflexões, discussões e suas próprias conclusões a respeito do experimento, desencadeando assim uma aprendizagem efetiva para os mesmos" (GÜLLICH; WALCZAK; MATTOS, 2016, p. 399). Para desencadear essa aprendizagem efetiva, o experimento deve ser contextualizado e reflexivo. Motta et al. (2013, p. 2) também descrevem de que forma a experimentação investigativa deve ocorrer na sala de aula:

\footnotetext{
A organização da experimentação investigativa na escola envolve trabalhar a partir de perguntas dos alunos e professor sobre os fenômenos da natureza em estudo. Essas perguntas oportunizam a construção de objetos aperfeiçoáveis, que trazem neles modelos de funcionamento desses objetos, o que possibilita questionamentos e argumentos que podem levar a melhor compreender o fenômeno e, com isso, aperfeiçoar este objeto produzido (MOTTA et al., 2013, p. 2).
}

Por meio da perspectiva investigativa, "os aspectos conceituais das disciplinas de Ciências com base em uma metodologia de ensino permitindo o levantamento de concepções dos estudantes (que podem ser primárias, parciais e mesmo alternativas) e a progressiva construção e reconstrução de conceitos" (OLIVEIRA; OBARA, 2018, p. 66). Entretanto, a experimentação não deve ser apenas de cunho investigativo: ela deve ser investigativa e contextual. Ou seja, além dele fazer uso da metodologia descrita acima, 
DOI: http://dx.doi.org/10.33238/ReBECEM.2020.v.4.n.1.24227

ele também deve fazer uso da reflexão crítica acerca do experimento em questão, pois "é por meio da sistematização/pesquisa das práticas, com o hábito da reflexão, que podem ser produzidos novos significados à experimentação, por isso é muito importante que o professor reflita sobre seus procedimentos de ensino" (WYZYKOWSKI; GÜLLICH, 2012, p. 6).

Com base em todos os excertos narrativos analisados, pudemos constatar que a experimentação é compreendida, por boa parte dos licenciandos, como concepção contextual-investigativa. No entanto, de modo geral, o número de outras concepções que emergiram supera a quantidade de concepções observadas na categoria contextualinvestigativa. A partir disso, podemos inferir que a formação inicial é muito importante para promover novos níveis de pensamento pedagógico, especialmente ao que se refere à experimentação no ensino de Ciências. Nesse sentido, segundo Maldaner (1999, p. 289), considerar as concepções que os licenciandos apresentam sobre esse tema tem sua importância, uma vez que orientam e/ou constituem posturas profissionais docentes e, se forem problematizadas à luz de avanços teóricos, poderão assumir importante papel na formação de novos professores. É por meio do aperfeiçoamento das concepções dos licenciandos que os avanços teóricos adquirem significados e concretude, permitindo que o futuro professor reflita sobre por quê e como utilizar a experimentação de forma que ocorra a construção de conhecimentos referentes às Ciências. Se ele não se depara com este tema durante o seu caminho formativo, certamente não fará o uso adequado/esperado das aulas experimentais, pois apresentará uma concepção equivocada acerca do papel das mesmas para a aprendizagem.

A partir dos resultados e análises acima, outro ponto que focalizamos neste estudo se refere às possibilidades de inter-relações entre as concepções de experimentação, Ciência e ensino expressadas nos excertos das escritas dos licenciandos. Segundo Maldaner (1999), há uma relação estreita entre a concepção que se tem de Ciência, sua produção e validação nas comunidades científicas e os processos de ensino e aprendizagem que são desenvolvidos no meio educacional.

Nesses termos, a prática pedagógica de cada professor manifesta suas concepções de ensino, aprendizagem e de conhecimento, bem como suas crenças, sentimentos, compromissos políticos e sociais. Por isso, as concepções de Ciências que, muitas vezes, orientam o ensino de Ciências no contexto escolar necessitam ser melhor caracterizadas, conhecidas, identificadas e analisadas em seu processo de evolução, para que se possa 


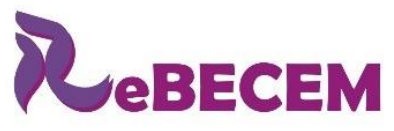

DOI: http://dx.doi.org/10.33238/ReBECEM.2020.v.4.n.1.24227
Revista Brasileira de Educação em

Ciências e Educação Matemática

articulá-las em prol da busca de solução às críticas apontadas a esse ensino relacionadas à sua pouca efetividade.

As concepções de Ciência foram categorizadas segundo Habermas (2006), referencial pelo qual identificamos nos excertos três categorias distintas, sendo elas: Concepção Empírico Analítica-Tradicional, Concepção Hermenêutica, Concepção Crítica, apresentadas na Figura 2.

Figura 2: Gráfico da Categorização das Concepções de Ciência

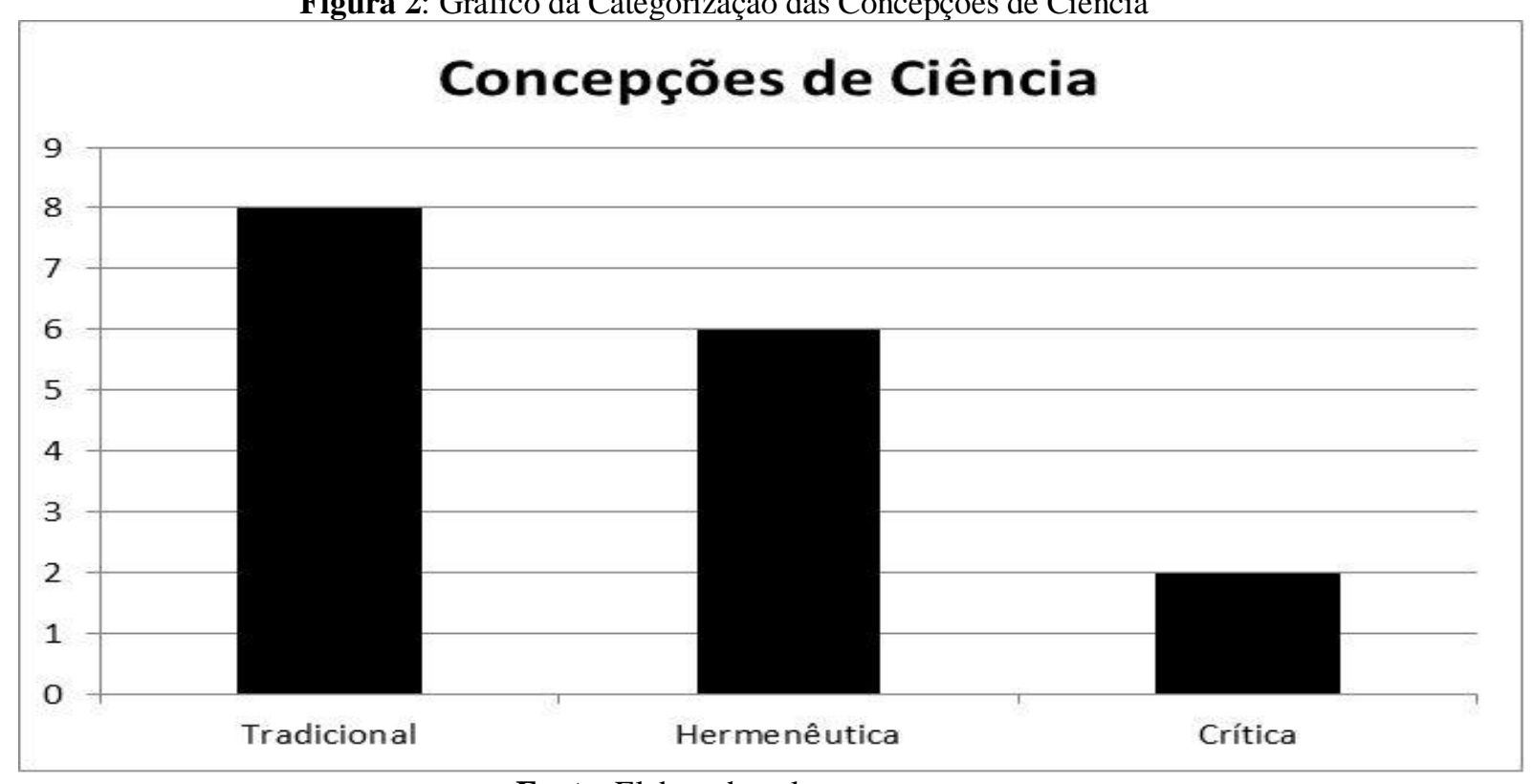

Fonte: Elaborado pelos autores

A Concepção Tradicional ou Empírico analítica é fundamentada em regras para a observação do experimento com o objetivo de comprovar hipóteses, sendo que a construção de conhecimentos parte da teoria para a prática, sendo a segunda banalizada, de natureza técnica e visa ao controle da natureza e da sociedade (HABERMAS, 2006). Muitos dos licenciandos que possuem esta concepção escreveram sobre as hipóteses e a importância da teoria, como verificamos em: “[...] é preciso ter uma base teórica para se comprovar essas hipóteses posteriormente” (L1) e “[...] preposições podem ser incorporadas, relacionando fenômenos, teorias" (L14).

Do total, oito licenciandos possuem essa concepção, a qual é a de maior expressão entre as categorias de concepção de Ciência. Podemos perceber que a concepção tradicional de Ciência apresenta características que se assemelham muito a algumas concepções de Experimentação como comprovação, demonstração e complementação da teoria, de racionalidade mais técnica. Também verificamos que todos os petianos que tiveram as suas concepções de experimentação assim caracterizadas apresentavam a 


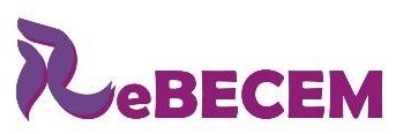

Revista Brasileira de Educação em

Ciências e Educação Matemática

DOI: http://dx.doi.org/10.33238/ReBECEM.2020.v.4.n.1.24227

concepção tradicional de Ciência. Isso decorre da forma como o professor concebe a experimentação, o que depende da sua visão de Ciência, pois experimentação e concepção de Ciências estão interligadas (ROSITO, 2008).

A Concepção Hermenêutica de Ciência valoriza a compreensão das coisas referentes à realidade e ao dia a dia, concebe o sujeito como interpretador, ou seja, o conhecimento advém das pesquisas e leituras que são interpretadas para a compreensão da realidade dos fatos e fenômenos que o contornam (HABERMAS, 2006). Dos excertos analisados, seis licenciandos possuem a concepção desta categoria. Em tais excertos, os licenciandos fazem referência à importância de o aluno pesquisar e ler também em casa, assim como de trabalhar de forma contextualizada. Como vemos a seguir: “[...] buscar esse aprendizado além da sala de aula [contexto ampliado]" (L2); “[...] levar o aluno a pesquisar o que está acontecendo ali, sendo assim muito importante para o processo de ensino-aprendizagem” (L16); "[...] mostrando para ele que o processo em questão pode não ser tão distante assim de sua realidade” (L8).

A maioria dos licenciandos com visão de experimentação como sinônimo de motivação apresentaram uma concepção hermenêutica da Ciência, de modo que em três dos quatro excertos foram identificadas palavras como "realidade", "dia a dia", "interpretação" e "fenômenos". Dos cinco petianos com a visão de experimentação como contextual-investigativa, três também apresentam a concepção de Ciência como hermenêutica, o que é muito importante tendo em vista a natureza contextual de ambos os tipos de concepção em termos conceituais. Em seus excertos, podemos encontrar palavras como "pesquisa" e "contexto", ou outras que denotam a importância do papel do aluno para a sua aprendizagem, pois, para que a pesquisa ocorra em sala de aula, o aluno precisa estar ativo no seu processo de aprendizagem.

Os outros dois petianos que tinham a concepção de experimentação como contextual-investigativa possuíam a concepção de Ciência como crítica, pois apresentavam em seus excertos palavras como "reflexão" e "questionamento", verificadas no excerto abaixo:

\footnotetext{
A experimentação no ensino de Ciências deve ser um momento de reflexão, na qual não pode existir uma receita de bolo a serem seguidas, apenas algumas orientações para que os estudantes possam por si mesmo realizar o experimento e questionar seus resultados (L12).
}

Essas palavras se relacionam e fazem referência à terceira concepção de Ciência, a Concepção Crítica, que, segundo Habermas (2006), examina as produções teóricas partindo do princípio da autorreflexão, assume a Ciência como uma construção humana 


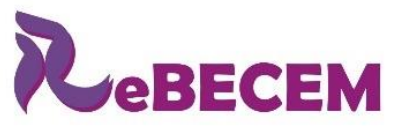

DOI: http://dx.doi.org/10.33238/ReBECEM.2020.v.4.n.1.24227

e, por isso, não é passível de ser neutra, portanto ela só produz verdades provisórias que podem ser refutadas por meio da reflexão crítica e constatação de novos conhecimentos. A produção do conhecimento, ao contrário das concepções anteriores, não enfatiza a teoria, como nem tampouco a prática, pois ambas precisam estar interligadas, visto que o sujeito é ativo na sua aprendizagem.

As Ciências e seu ensino têm sofrido grandes mudanças, tornando-se mais complexos e exigindo novos perfis dos professores na atualidade. Entretanto, a análise dos resultados que obtivemos indicou que a maioria dos professores em formação inicial ainda possui uma visão tradicional de Ciência. E isso se reflete na forma como atuam, pois essa visão ajuda a definir a sua visão de experimentação, que acaba sendo mais fechada, centrada em si mesma e não no aluno, não contribuindo ou contribuindo muito pouco para o processo de aprendizagem em Ciências.

Assim como as concepções de Ciência e de experimentação estão interligadas, as concepções de ensino são reflexos de todas as concepções que fazem parte do professor e definem sua prática, pelo que também numa via de mão-dupla influenciam as demais concepções. "Esta interação pressupõe uma visão teórica sobre o que é ser professor, quem é o sujeito que aprende [aluno(a)], como se constitui o processo de ensino e de aprendizagem e sobre a natureza do conteúdo que se ensina na sala de aula" (ROSA; SCHNETZLER, 2003, p. 29).

Durante a análise dos excertos dos licenciandos participantes da investigação, emergiram três categorias para a Concepção de Ensino dos mesmos, sendo elas: Transmissão de conhecimentos, Significação de conhecimentos e Processo dialógico de construção de saberes. A categoria mais expressiva foi a que compreende o ensino como um processo de transmissão de conhecimentos, manifestada por sete dentre os dezesseis licenciandos investigados, que se distribuem pelas três categorias, conforme mostra a Figura 3. 
DOI: http://dx.doi.org/10.33238/ReBECEM.2020.v.4.n.1.24227

Figura 3: Gráfico de categorização das concepções de ensino

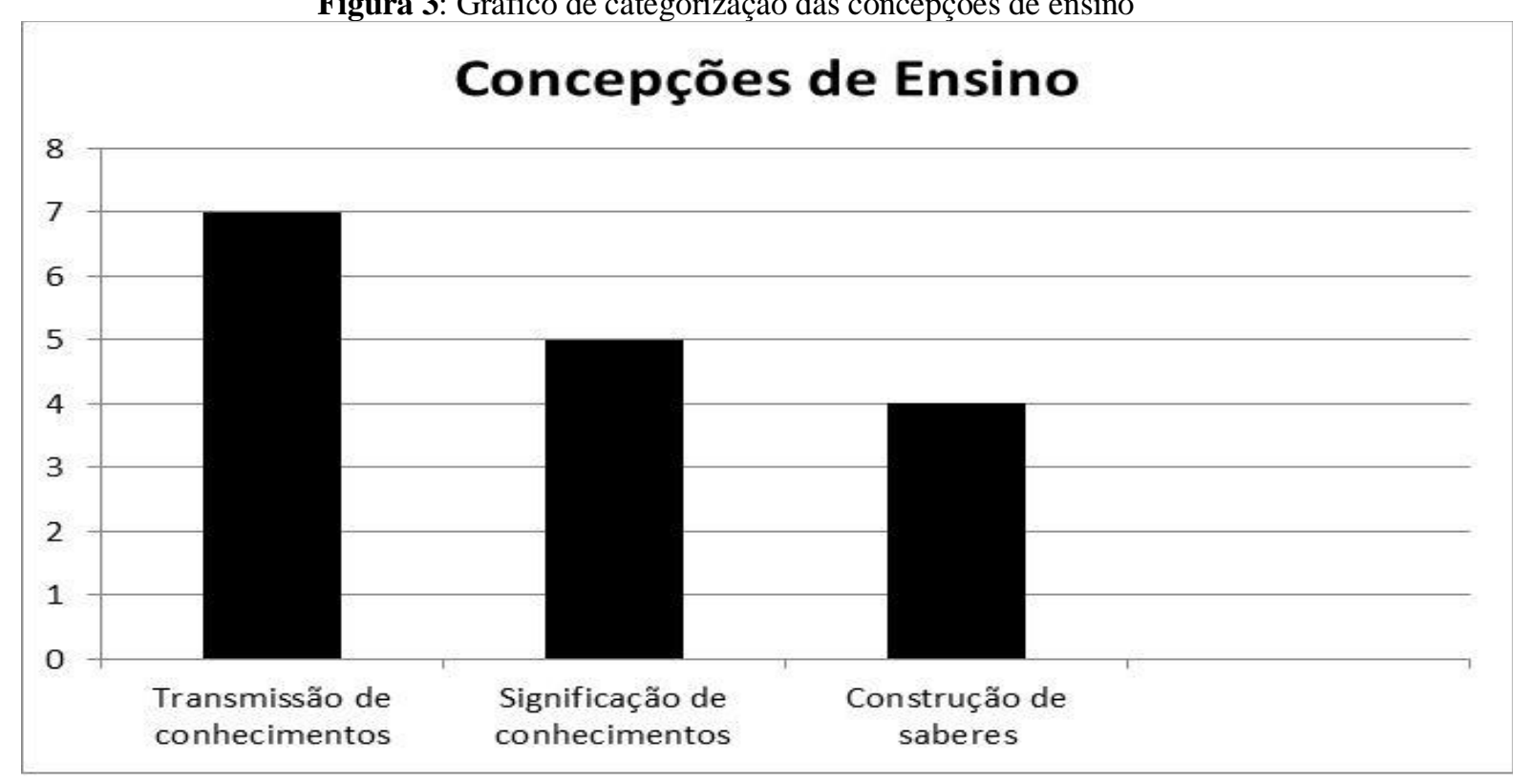

Fonte: Elaborado pelos autores

Segundo Rosa e Schnetzler (2003), aqueles professores que concebem o ensino como mera Transmissão de Conhecimentos compreendem a investigação educativa pelo modelo da racionalidade técnica. Segundo este modelo, "a atividade profissional consiste na solução instrumental de um problema feita pela rigorosa aplicação de uma teoria científica ou uma técnica" (SCHÖN 1983, p. 21). Neste contexto, a educação é vista como uma Ciência aplicada, as questões educacionais são vistas como problemas técnicos e são resolvidas através da racionalidade científica (CARR; KEMMIS, 1986).

Os licenciandos que assim concebem o ensino tiveram em seus excertos como caraterística a predominância de palavras como "comprovar" e "mostrar/demonstrar", sendo que as mesmas eram empregadas de forma a deixar explícito que o professor era o detentor do conhecimento científico, tendo como papel transmitir tal conhecimento a seus alunos, como fica evidente em: "[...] é uma ferramenta para que os alunos possam ver como a teoria pode ser provada e assim compreender melhor o conhecimento científico" (L3). A maioria desses licenciandos também apresentou a concepção de experimentação como comprovação da teoria, motivadora ou demonstrativa, ou seja, ainda possuem concepções mais simplistas.

Já os professores que desenvolvem as suas atividades apoiadas na racionalidade prática, compreendem que a educação é um processo complexo (ROSA; SCHNETZLER, 2003), uma atividade que é modificada de acordo com as circunstâncias e a decisão da modificação cabe ao professor. Essa visão compreende as diferentes realidades 
DOI: http://dx.doi.org/10.33238/ReBECEM.2020.v.4.n.1.24227

educacionais e, sendo assim, os problemas não podem ser resolvidos de forma técnica e demandam reflexão (CARR; KEMMIS, 1986).

Tal visão admite que existem várias técnicas que ajudam o professor durante o processo de produção de aprendizagem. No entanto, o conhecimento que estes profissionais devem ter para alcançar esta produção vai muito além de um conjunto de técnicas, como ressaltam Carr e Kemmis:

\begin{abstract}
O conhecimento profissional dentro dessa visão não consiste em projetar um conjunto de objetivos sequenciados e técnicas as quais "dirigem" os aprendizes para os resultados da aprendizagem esperada. Ele consiste da direção e redireção espontânea e flexível do processo da aprendizagem, guiada por uma leitura sensível das mudanças sutis e da reação de outros participantes desse processo (CARR; KEMMIS, 1986, p. 37).
\end{abstract}

$\mathrm{Na}$ perspectiva prática, situam-se dois tipos de concepção de ensino que emergiram da análise: uma em que os petianos a entendem como a significação de conhecimentos e outra como um processo dialógico de construção de saberes (ROSA; SCHNETZLER, 2003), como veremos na análise que segue.

Segundo Freire (1998), a aprendizagem é alcançada pela mediação do professor frente aos significados que emergem das falas dos alunos durante as aulas. Assim, dentre os licenciandos investigados, cinco apresentavam em seus excertos a concepção de ensino como Significação de Conhecimentos. Apesar de serem identificadas palavras como: "comprovar" e "demonstrar", seus excertos continham também as palavras "significado" e "compreensão", ou expressões que apontavam para a importância de que os conteúdos tivessem alguma significação ou relação com o cotidiano dos alunos, para que a aprendizagem de fato ocorresse, reafirmando a importância do professor como mediador deste processo, como pode ser verificado em: “[...] pela mediação qualificada do professor conhecimentos tornam-se significados e que de fato façam sentido para os alunos" (L19) e "[...] facilita a compreensão e entendimento de conceitos que muitas vezes são abstratos, ou fenômenos que ocorrem no seu dia a dia” (L6).

Fica visível como a concepção de Ciência hermenêutica e a concepção de ensino como significação de conhecimentos se aproximam em relação as suas características, pois ambas levam em conta o papel do aluno para a sua aprendizagem e a importância de o professor mediador relacionar os conhecimentos de sala de aula com o cotidiano do aluno. Por isso, muitos dos licenciandos com a concepção hermenêutica apresentaram a concepção de ensino como sendo a significação de conhecimentos ou detinham traços da mesma em seus excertos, o que mostra que as concepções estão interligadas e podem evoluir conjuntamente. Mas, isto não é regra, pois algumas concepções podem demorar 


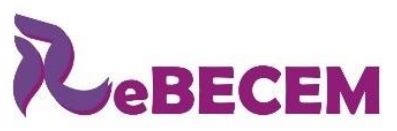

Revista Brasileira de Educação em

Ciências e Educação Matemática

DOI: http://dx.doi.org/10.33238/ReBECEM.2020.v.4.n.1.24227

mais a evoluir do que as outras e nem todas que se assemelham seguiram um mesmo caminho/processo de desenvolvimento.

Já os professores que concebem o ensino como um Processo Dialógico de Construção de Saberes (ROSA; SCHNETZLER, 2003) foram no total de quatro, representando a minoria. Seus excertos apresentavam palavras como "problematização", “construir", "refletir" e "questionar", assim como frases que deixavam implícita a ideia de que durante o processo de experimentação (um tipo de ensino) a sistematização do conhecimento e o diálogo são importantes. A escrita dos professores em formação, aqui anlisada, permitiu um processo de reflexão, culminando no avanço de suas concepções. Pois, a reflexão sobre as atividades de ensino contempladas na escrita possibilitou a reestruturação do pensamento dos petianos, por meio do registro e a comunicação de conhecimentos (TRIVELATO; TONIDANDEL, 2015).

As atividades realizadas no PETCiências assumem relevância quando consideramos que "O respeito a diferentes concepções explicitadas nos diálogos [...] era algo precioso para a manutenção de uma construção coletiva de saberes" (ROSA; SCHNETZLER, 2003 p. 37). Isto pode ser verificado no excerto asseguir: É uma ferramenta muito interessante como problema instigante quando abordada no primeiro momento pedagógico, para levar o aluno a pesquisar o que está acontecendo ali” (L16) e no excerto noutr excerto:

A experimentação no ensino de Ciências é uma metodologia de ensino muito
utilizada, pois a partir da mesma é possível visualizar fenômenos, construir
conceitos e então facilitar a construção dos conhecimentos dos estudantes. A
experimentação no ensino de Ciências deve ser um momento de reflexão, na
qual não pode existir uma receita de bolo a serem seguidas, apenas algumas
orientações para que os estudantes possam por si mesmo realizar o
experimento e questionar seus resultados (L12).

Verificamos que a concepção de ensino como processo dialógico de construção de saberes está muito relacionada à concepção de experimentação como contextualinvestigativa, pois ambas se baseiam em diálogo, reflexão e questionamento para conduzir o processo de aprendizagem. Podemos perceber, também, que alguns licenciandos possuem a concepção de Ciência tradicional, no entanto a sua concepção de ensino se apresenta como processo dialógico de construção de saberes, em função de explicitar a importância da "contextualização" e da "sistematização" do conhecimento em sala de aula. Isto mostra que, mesmo pensando em aulas tradicionais, alguns licenciandos já começam a ter uma abertura, planejando um ensino mais elaborado e, assim, aos poucos avançando nas suas concepções. 


\section{Conclusão}

As concepções de ensino são reflexos de todo o conhecimento que faz parte do professor, definem sua prática e influenciam as demais concepções. Foi possível verificar certa tendência entre os licenciandos, sendo os que concebiam a Ciência como hermenêutica entendiam o ensino como significação de conhecimentos; já os que viam a Ciência como crítica, concebiam o ensino como um processo dialógico de construção de saberes e a experimentação era vista como contextual-investigativa. Compreendemos, assim, que as concepções estão interligadas e, muitas vezes, tendem a avançar e retroceder conjuntamente. Foi possível verificar também que a concepção de Ciência tradicional se reflete na forma como os licenciandos atuam, interferindo também na concepção de experimentação que acaba sendo mais fechada e tradicional, pouco investigativa e contextual. No entanto, a concepção de experimentação não exerce tanta expressão na determinação das concepções de ensino, sobre as quais podemos notar um avanço maior à medida que as ações no grupo de leitura e formação são desenvolvidas.

Além do exposto acima, podemos perceber que as concepções de Ciência tendem a demorar mais para avançar do que as concepções de ensino e de experimentação. Por isso, muitos licenciandos ainda percebem a Ciência como tradicional, mas já avançam no seu movimento discursivo, apresentando concepções de ensino e de experimentação mais contextuais. Nesse sentido, acreditamos que o movimento discursivo em relação às concepções não é linear. Nele ocorrem muitas incongruências, diferenças e descompassos. Em alguns casos também percebemos a presença de duas categorias dentro das concepções de um licenciando, mostrando um possível momento de avanço ou retrocesso, no entanto uma sempre se faz prevalecer.

Podemos constatar ainda, no coletivo de formação investigado (PETCiências), que a experimentação em sua maioria é compreendida como concepção contextualinvestigativa, sendo verificado também que os licenciandos que apresentam tal concepção são os que já estão há mais tempo vivenciando o programa, ou realizaram pesquisas sobre o tema. Assim, visando aperfeiçoar as concepções dos licenciandos, defendemos: i) o papel do contato com a escola que os licenciandos tiveram; ii) as leituras de referências sobre a temática da experimentação; iii) a escrita reflexiva (neste caso, analisadas as do Facegrupo); iv) o diálogo formativo exercido durante os encontros semanais do PETCiências; v) o processo de mediação formativa que o tutor do programa e 


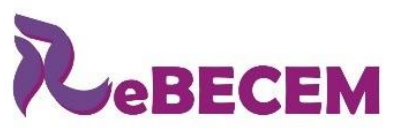

Revista Brasileira de Educação em

Ciências e Educação Matemática

DOI: http://dx.doi.org/10.33238/ReBECEM.2020.v.4.n.1.24227

colaboradores exercem como professores formadores, como sendo elementos cruciais para melhoria da formação inicial em Ciências.

Portanto, podemos inferir que a formação inicial é muito importante por propiciar o diálogo sobre o papel da Experimentação, da Ciência e do Ensino em si, bem como a aprendizagem acerca do papel da experimentação para as Ciências e para o ensino, possibilitando ao licenciando aprender e refletir sobre por quê e como utilizar a experimentação de forma que ocorra a construção de conhecimentos em Ciências. Se ele não se depara com estas discussões durante o seu caminho formativo, terá menos condições e oportunidades de reconstruir/ressignificar suas concepções, prejudicando processos de ensino e aprendizagem nas aulas de Ciências. Acreditamos que, tratando a experimentação de modo contextual e investigativo, os professores vão também contextualizar a Ciência que ensinam e, desta forma, o ensino de Ciências tende a adquirir novos significados.

\section{Referências}

ALARCÃO, I. Professores reflexivos em uma escola reflexiva. 7. ed. São Paulo: Cortez, 2010.

ARAÚJO, M. S. T; ABIB, M. L. V. S. Atividades Experimentais no Ensino de Física: diferentes enfoques, diferentes finalidades. Revista Brasileira de Ensino de Física, São Paulo, v.25, n.2, p.176-194, 2003. Disponível em: http://www.scielo.br/pdf/rbef/v25n2/a07v25n2.pdf. Acesso em: 12 fev. 2019.

CARR, W. KEMMIS, S. Becoming critical: education, knowledge and action research. London: The Falmer Press, 1986.

CARVALHO, A. M. P. et al. Ciências no Ensino Fundamental: o conhecimento físico. São Paulo: Scipione, 2007.

FAGUNDES, S. M. K. Experimentação nas aulas de Ciências: um meio para a formação da autonomia? In: GALIAZZI, M. C. et al. Construtivismo curricular em rede na educação em ciências: uma aposta de pesquisa na sala de aula. Ijuí: Unijuí, 2007. p. 317-336.

FREIRE, P. Pedagogia da Autonomia: saberes necessários para a prática educativa. 9.ed. Rio de Janeiro: Paz e Terra. 1998.

GASPAR, A.; MONTEIRO, I. C. C. Atividades experimentais de demonstração em sala de aula: uma análise segundo o referencial da teoria de Vigotsky. Investigações em Ensino de Ciências, Porto Alegre, v.10, n.2, p. 227-254, 2005. Disponível em:

https://www.if.ufrgs.br/cref/ojs/index.php/ienci/article/view/518/315. Acesso em: 12 fev. 2019.

GONÇALVES, F. P.; GALIAZZI, M. C. A natureza das atividades experimentais no ensino de ciências: um programa de pesquisa educativa nos cursos de licenciatura. In: MORAES, R.; MANCUSO, R. (org). Educação em ciências: produção de currículos e formação de professores. Ijuí: Editora Unijuí, 2004. p. 237-252. 


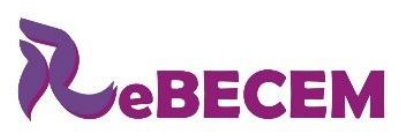

\section{Revista Brasileira de Educação em \\ Ciências e Educação Matemática \\ ISSN 2594-9179}

DOI: http://dx.doi.org/10.33238/ReBECEM.2020.v.4.n.1.24227

GÜLLICH, R. I. C. Investigação-Formação-Ação em Ciências: um caminho para reconstruir a relação entre livro didático, o professor e o ensino. Curitiba: Editora Prismas Ltda, 2013.

GÜLLICH, R. I. C.; SILVA, L. H. A. O Enredo da Experimentação no Livro Didático: Construção de conhecimentos ou Reprodução de Teorias e Verdades Científicas? Revista Ensaio pesquisa em Educação em Ciências, Belo Horizonte, v.15. n. 2, p. 155-167, 2013. Disponível em: http://www.scielo.br/pdf/epec/v15n2/1983-2117-epec-15-02-00155.pdf. Acesso em: 12 fev. 2019.

GÜLLICH, R. I. C.; WALCZAK, A.; MATTOS, K. R. C. Experimentação investigativa nos livros didáticos de biologia. Revista da SBEnBio, n. 9, p. 392-403, 2016. Disponível em: https://sbenbio.org.br/wp-content/uploads/edicoes/revista_sbenbio_n9.pdf. Acesso em: 12 fev. 2019.

HABERMAS, J. Conhecimento e Interesse. In: HABERMAS, J. Técnica e ciência como “ideologia". Lisboa: Edições 70. s.d., 2006. p. 129-147.

HODSON, D. Hacia un enfoque más crítico del trabajo de laboratório. Enseñanza delas Ciencias, v.12, n. 13, p. 299-313, 1994. Disponível em:

https://www.raco.cat/index.php/Ensenanza/article/view/21370/93326. Acesso em: 12 fev. 2019.

LÜDKE, M.; ANDRÉ, M. E. D. A. Pesquisa em educação: abordagens qualitativas. São Paulo: Epu, 2001.

MALDANER, O. A. A pesquisa como perspectiva de formação continuada do professor de química. Química Nova, São Paulo: SBQ, v. 22, n. 2, p. 289-292, 1999.

MOTTA, C. S. et al. Experimentação investigativa: indagação dialógica do objeto aperfeiçoável. ENCONTRO NACIONAL DE PESQUISA EM EDUCAÇÃO EM CIÊNCIAS, 9., 2013, São Paulo. Anais... São Paulo: Majestic, 2013. Disponível em:

http://www.nutes.ufrj.br/abrapec/ixenpec/atas/resumos/R1187-1.pdf. Acesso em: 12 fev. 2019.

OLIVEIRA, A. L.; OBARA, A. T. O ensino de ciências por investigação: vivências e práticas reflexivas de Professores em formação inicial e continuada. Revista Investigações em Ensino de Ciências, Porto Alegre, v. 23 n. 2, p. 65-87, 2018. Disponível em:

https://www.if.ufrgs.br/cref/ojs/index.php/ienci/article/view/874. Acesso em: 05 ago. 2019.

OLIVEIRA, J. R. S. Contribuições e abordagens das atividades experimentais no ensino de ciências: reunindo elementos para a prática docente. Acta Scientiae, Canoas, v.12, n.1, p. 139156, 2010. Disponível em: <http://www.periodicos.ulbra.br/index.php/acta/article/view/31/28>. Acesso em: 12, fev. 2019.

PHILLIPS, B.S. Pesquisa Social. Rio de Janeiro: Agir, 1974.

RAMOS, L. S.; ANTUNES, F.; SILVA, L. H. A. Concepções de professores de ciências sobre o ensino de ciências. Revista da SBEnBio, n. 03, p. 1666- 1674, 2010. Disponível em: https://sbenbio.org.br/wp-content/uploads/edicoes/revista_sbenbio_n3/B056.pdf. Acesso em: 12 fev. 2019.

RIBAS, C. P.; UHMANN, R. I. M. Aulas práticas/teóricas em ciências: uma memória reflexiva na formação docente. ENCONTRO REGIONAL DE ENSINO DE BIOLOGIA, 6., 2013, Santo Ângelo. Anais... Santo Ângelo: URI, 2013. Disponível em:

$<$ http://santoangelo.uri.br/erebiosul2013/anais/wpcontent/uploads/2013/07/comunicacao/13318_24_claudio_pereira_ribas.pdf $>$. Acesso em: 12 fev. 2019. 
DOI: http://dx.doi.org/10.33238/ReBECEM.2020.v.4.n.1.24227

ROSA, M. I. F. P. S.; SCHNETZLER, R. P. A investigação-ação na formação continuada de professores de ciências. Ciência e educação, Bauru, v.9, n.1. p.27-39, 2003. Disponível em: http://www.scielo.br/pdf/ciedu/v9n1/03.pdf. Acesso em: 21 set. 2018.

ROSITO, B. A. O ensino de Ciências e a experimentação. In: MORAES, R. (org.). Construtivismo e ensino de ciências: reflexões epistemológicas. 3. ed. Porto Alegre: EDIPUCRS, 2008. p. 195-208.

SCHÖN, D. The reflective practitioner. New York: Basic Books, 1983.

SILVA, L. A. S.; ZANON, L. B. A experimentação no ensino de ciências. In: SCHNETZLER, R. P.; ARAGÃO, R. M. R. (org.). Ensino de ciências: fundamentos e abordagens. São Paulo, Ed. CAPES/UNIMEP, 2000. p.120-153.

SILVA, M. B.; GEROLIN, E. C.; TRIVELATO, S. L. F. A Importância da Autonomia dos Estudantes para a Ocorrência de Práticas Epistêmicas no Ensino por Investigação. Revista Brasileira de Pesquisa em Educação em Ciências, v. 18, n. 3, p. 905-933, 2018. Disponível em: https://periodicos.ufmg.br/index.php/rbpec/article/view/4817. Acesso em: 05 ago. 2019.

TARDIF, M. Saberes docentes e formação profissional. Petrópolis: Vozes, 2002.

TRIVELATO, S. L. F.; TONIDANDEL, S. M. R. Ensino por investigação: eixos organizadores para sequências de ensino de biologia. Revista Ensaio pesquisa em Educação em Ciências, v.17, n. spe., p. 97-114, 2015. Disponível em:

http://www.scielo.br/scielo.php?script=sci_abstract\&pid=S1983-

$21172015000400097 \& \operatorname{lng}=$ en\&nrm=iso\&tlng=pt. Acesso em: 05 ago. 2019.

WYZYKOWSKI, T.; GÜLLICH, R. I. C. Compreendendo concepções de experimentação no processo de iniciação a docência em ciências. Revista da SBEnBIO, v. 5, p. 1- 8, 2012.

Disponível em: https://sbenbio.org.br/wp-

content/uploads/edicoes/revista_sbenbio_n5/arquivos/3710.pdf. Acesso em: 06 ago. 2019.

WYZYKOWSKI, T.; GÜLLICH, R. I. C.; ARAÚJO, M. C. P. Compreendendo a experimentação em Ciências: entre o discurso e a prática. Revista de Educación en Biología, Córdoba, v. 19, n. 1, p. 35-53, 2016. Disponível em:

http://www.revistaadbia.com.ar/ojs/index.php/adbia/article/view/399/pdf. Acesso em: 12, fev. 2019.

Recebido em: 11 de março de 2020

Aceito em: 16 de março de 2020 